\title{
Acrocephalopolysyndactyly, pentalogy of Fallot, and hypoacusis in a patient with a de novo reciprocal translocation involving the short arm of chromosome 1 and the long arm of chromosome 18: 46,XX,t $(1 ; 18)(\mathrm{p} 31 ; \mathrm{q} 11)$
}

John Ward, Eduardo Vieto, David Lee, Gloriela Arosemena

\begin{abstract}
We present a female patient with acrocephalopolysyndactyly, pentalogy of Fallot, psychomotor retardation, and hypoacusis with a de novo, apparently balanced, reciprocal translocation $46, X X, t(1 ; 18)(p 31 ; q 11)$. ( $\mathcal{H}$ Med Genet 1993;30:438-9)
\end{abstract}

The acrocephalopolysyndactyly syndromes can show autosomal dominant or autosomal recessive inheritance. We present a patient with acrocephalopolysyndactyly with other associated anomalies such as pentalogy of Fallot, hypoacusis, psychomotor retardation, and a de novo, apparently balanced, reciprocal translocation involving chromosomes 1 and 18.

\section{Case report}

The proband was an 11 year old female, the product of a term pregnancy of a 21 year old, gravida 4, para 3, abortus 1 mother and a nonconsanguineous 29 year old father, both in good health. The two older sibs of the patient were normal and healthy. The labour and delivery were complicated by perinatal asphyxia and the birth weight was $2610 \mathrm{~g}$.

The patient was first seen in our institution at the age of 3 months. Physical examination at that time showed a head circumference of $39.5 \mathrm{~cm}$ (50th centile) and a length of $59 \mathrm{~cm}$ (50th centile). Examination of the hands and feet showed preaxial polydactyly on all the extremities with syndactyly $2 / 3$ on the left foot (fig 1). A grade $2 / 6$ systolic ejection murmur was heard over the left precordium.

She sat at 19 months of age and walked at 2 years 7 months. She was treated for generalised febrile convulsions resulting from acute extracranial infection at 17 months of age. Her supernumerary fingers and toes were removed from both hands and feet with correction of the syndactyly of the left foot.

Plain skull radiographs showed oxycephaly with synostosis of the coronal and lambdoid sutures. CT scan at the age of 4 years showed partial agenesis of the corpus callosum. ECG showed biventricular hypertrophy and cardiac catheterisation showed pentalogy of Fallot. Free field hearing test suggested medium to profound hypoacusis. At the age of 4 years old, she had a palliative Blalock-Taussing operation.

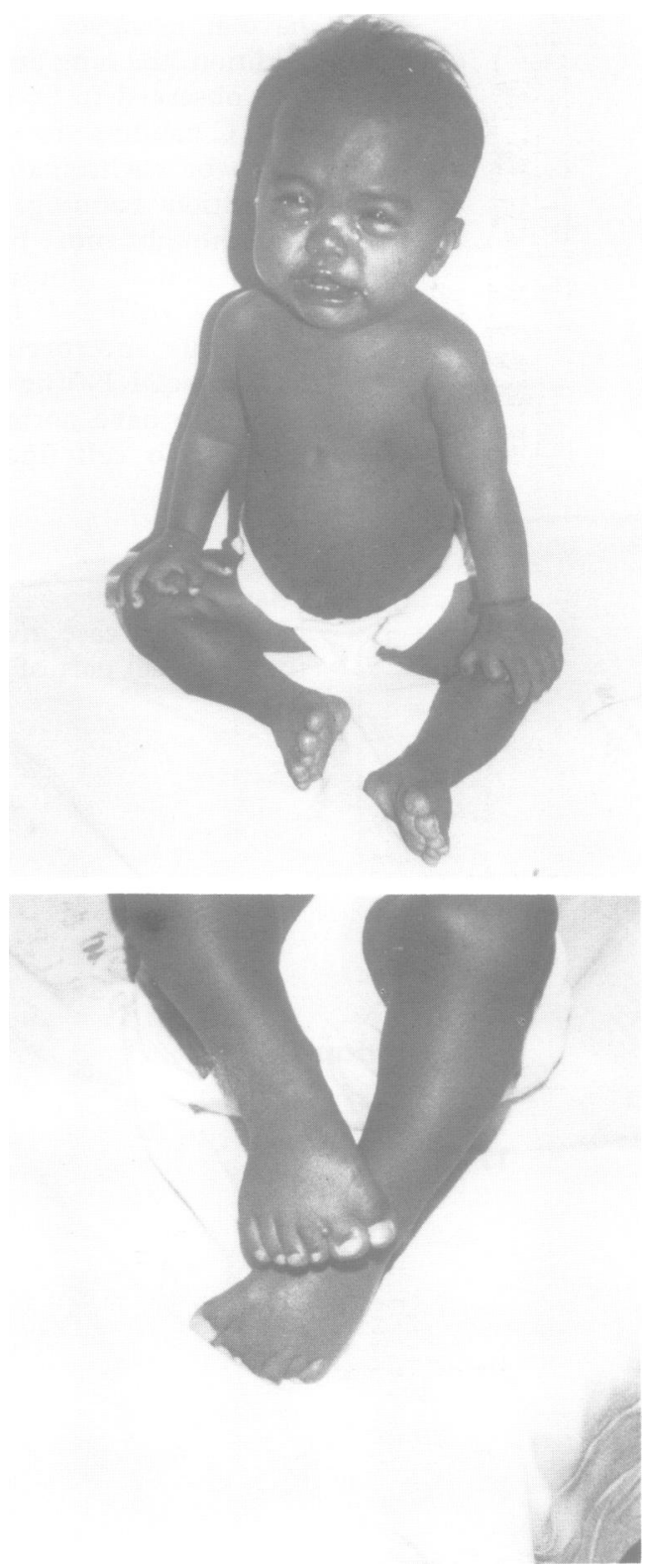

Figure 1 The patient at 19 months of age, showing preaxial polydactyly of both hands and both feet with syndactyly $2 / 3$ on the left foot.

Physical examination showed acrocephaly and the hands and feet showed scars of previous operations. She has a $2 / 6$ systolic ejection murmur, heard best at the lower left sternal border. Her vocabulary is non-existent. 
CYTOGENETIC STUDIES

$G$ banding studies showed an apparently balanced reciprocal translocation involving the short arm of chromosome 1 and the long arm of chromosome 18: $46, \mathrm{XX}, \mathrm{t}(1 ; 18)(\mathrm{p} 31 ; \mathrm{q} 11)$ (fig 2). The karyotype of both parents was normal. No cell line is available from this patient.

\section{Discussion}

The clinical features of our patient are acrocephaly, preaxial polydactyly of all extremi-
A
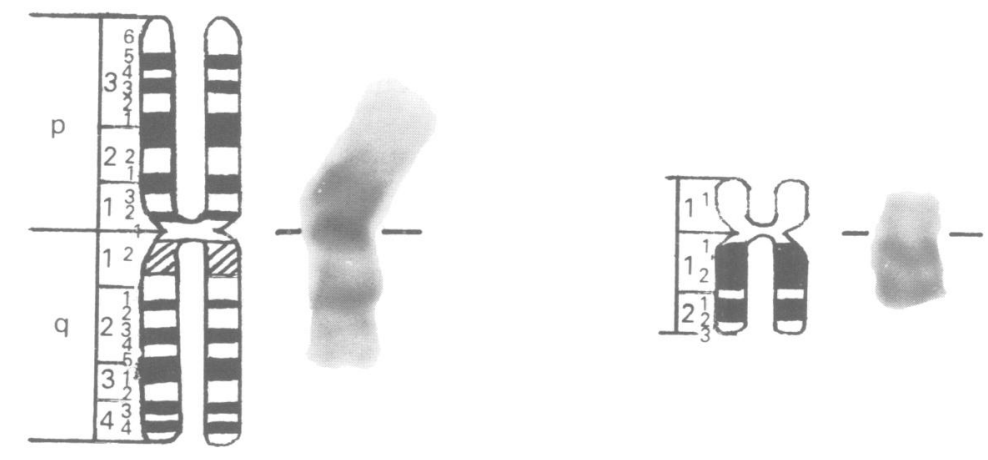

B
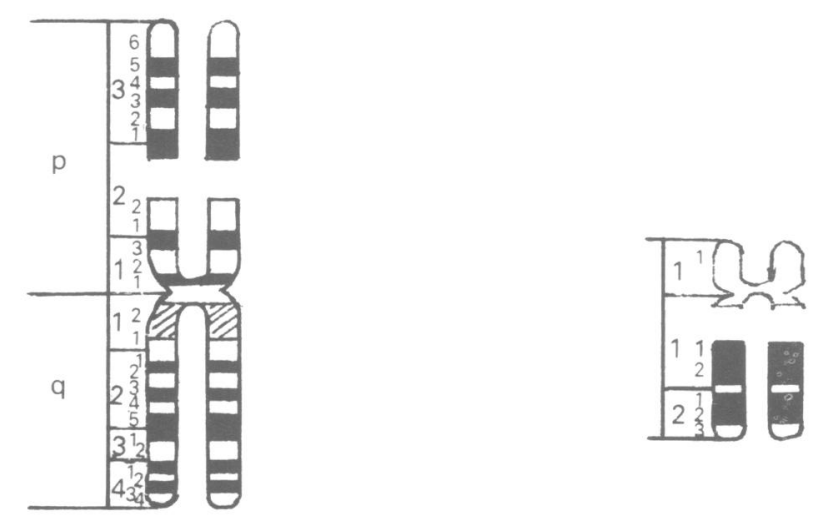

C

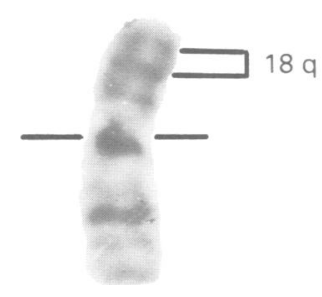

Figure 2 Partial karyotype ( $G$ banding) and diagram. ( $A$ ) Normal chromosomes 1 and 18. (B) Diagram of breakpoints on chromosomes 1 and 18. (C) Reciprocal translocation $t(1 ; 18)(p 31 ; q 11)$.] Material from 18 translocated onto 1,$\}$ Material from 1 translocated onto 18. ties, syndactyly $2 / 3$ on the left foot, hypoacusis, pentalogy of Fallot, partial agenesis of the corpus callosum, and severe psychomotor retardation.

Schinzel acrocallosal syndrome includes many features seen in our patient, such as agenesis of the corpus callosum, severe mental retardation, and the digital manifestations, ${ }^{1}$ but the hypoacusis and pentalogy of Fallot preclude this diagnosis.

The difference between our patient and the Greig cephalopolysyndactyly syndrome is that, in the latter, mental retardation, when present, is mild and has been reported in only a few cases and only one case has been described with agenesis of the corpus callosum. ${ }^{23}$ It has been confirmed that Greig syndrome maps to 7p13. ${ }^{4}$

The features in our patient are very similar to those of Carpenter syndrome, including acrocephaly, digital manifestations, mental retardation, and the congenital heart defect. Hearing loss occurs occasionally in Carpenter syndrome, but the partial agenesis of the corpus callosum present in our patient is not a feature of the Carpenter syndrome.

Bovicelli et al $^{5}$ in 1980 reported a prenatally diagnosed de novo translocation involving chromosomes 1 and 18 . Because of the risk of abnormality, the fetus was aborted and subsequently found to have no malformation. Other apparently balanced translocations involving chromosomes 1 and 18 with different breakpoints have been reported ${ }^{67}$; however, the phenotypes were apparently normal. To our knowledge, the present case is the first report of phenotypic abnormalities associated with a de novo balanced reciprocal translocation involving chromosomes 1 and 18 .

It is possible that the phenotypic and cytogenetic findings in this patient are related. Further documentation of phenotypic abnormalities in subjects with the same balanced reciprocal translocation is needed to confirm this, as it is also possible that the association of the chromosomal abnormalities and the phenotypic syndrome may be purely coincidental.

1 Schinzel A, Kaufmann U. The acrocallosal syndrome in sisters. Clin Genet 1986;30:399-405.

2 Baraitser M, Winter RM, Brett EM. Greig cephalopolysyndactyly: report of 13 affected individuals in three families. Clin Genet 1983;24:257-65.

3 Jones KL. Greig cephalopolysyndactyly syndrome. In: Smith's recognizable patterns of human malformation. Philadelphia: Saunders, 1988.

4 McKusick VA. Mendelian interitance in man. Catalogs of autosomal dominant, autosomal recessive, and $X$ linked phenotypes. 9th ed. Baltimore; Johns Hopkins University notypes. 9th

5 Bovicelli L, Orsini LF, Rizzo N, Montacuti V, Bacchetta M. Prenatal diagnosis of a de novo reciprocal translocation Prenatal diagnosis of a de novo reciprocal translocation
$46, X X, t(1 ; 18)(p 22 ; q 23)$. Clin Genet $1980 ; 18: 434-5$.

6 Breg WR, Miller DA, Allderdice W, Miller OJ. Identification of translocation chromosomes by quinacrine fluores-
tren cence. Am ₹ Dis Child 1972;123:561-4.

7 Chandley AC, Fletcher JM. Centromere staining in man. Humangenetik 1973;18:247-52. 